\title{
Academic Endowments and Focused Learning: Initial Experiences within a Manufacturing Engineering Program
}

\author{
J.E. Johnson, L. Stradins, S. Springer and R. Asthana \\ Department of Engineering and Technology, University of Wisconsin-Stout \\ Menomonie, WI 54751 \\ johnsonj@uwstout.edu
}

\begin{abstract}
In the spring of 2012, the University of Wisconsin-Stout authorized the Department of Engineering and Technology to establish the second of the two endowed chairs in manufacturing engineering. The creation of the chair was made possible by a generous endowment from the estate of Fulton and Edna Holtby. The goal was to promote professional activities of students, faculty, and staff in areas of research, scholarship, course development and professional development by providing funds for stipend, travel, buyout for release time and purchase of equipment, services and supplies. These funds were to be used to offer undergraduate and graduate students opportunity to explore special topics outside of their formal coursework that inspired their creativity and imagination through additional research and exploration and earn college credit for their work. As structured coursework rarely offers extended, stress-free environment conducive to learning and exploration, ideas were developed for student projects to provide laboratory-based research experiences that offered excitement of learning and innovation in multiple areas of manufacturing. Emphasis was placed on dissemination of student research. The paper highlights examples of completed student projects and articulates a vision for use of endowment funds to facilitate student learning and faculty development in a student-centered environment.
\end{abstract}

\section{Introduction}

As a special mission institution within the University of Wisconsin System, the University of Wisconsin-Stout is a comprehensive, career-focused polytechnic university with historic strengths in applied learning and technology. The university's manufacturing engineering B.S. degree program is one of the largest ABET-accredited programs in the nation [1]. Stout's program is the only undergraduate program in manufacturing engineering in the entire University of Wisconsin System. The B.S. in manufacturing engineering program at UW-Stout began officially in the fall of 1994. The university also offers a M.S. degree in manufacturing engineering.

UW-Stout's manufacturing engineering B.S. and M.S. degree programs are offered by the Department of Engineering and Technology. The department manages two endowed chair positions: George Albert Taft Chair and Fulton and Edna Holtby Chair. The initial appointments to these chairs are for three years. The Taft Chair is named in honor of G.A. Taft and was endowed by his daughter, Esther Quinn, and her husband, Robert Quinn. Taft was associated with the Dunn County News in Menomonie before establishing DeLuxe Check Printers in the Twin Cities area. 


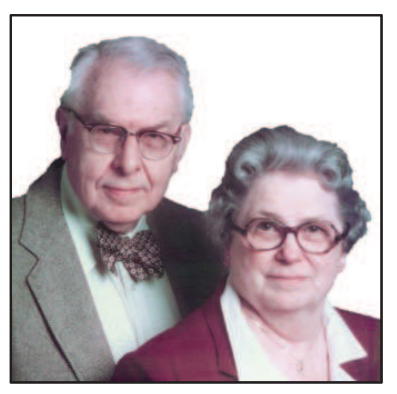

Fig. 1 Fulton and Edna Holtby

The creation of the Holtby chair was made possible by a generous endowment from the estate of Fulton Holtby, a former professor of mechanical engineering at the University of Minnesota for 41 years, and his wife, Edna Holtby (Fig. 1). Fulton was a highly sought-after educator and an expert forensics engineer. He truly loved the hands-on approach to learning, to make sure young people got to actually work on the products. Fulton is credited with designing and building the first aircraft flight recorder and the first heart valve replacements and special suture clamps for heart surgery, and models for a courtroom exhibit in a $\$ 2$ billion lawsuit on the Amoco Cadiz oil spill. At age 90, he perfected a metal casting process that resulted in significant reduction in cost, weight and waste material. For decades, Fulton supported Stout's technical programs, generously funding several hundred scholarships for engineering students. A museum in Menomonie, WI dedicated to Fulton and Edna Holtby features Fulton's extensive shop and collections of working steam and marine engine models.

The Fulton and Edna Holtby Chair was established in the spring of 2012 with endowment funds earmarked specifically for the manufacturing engineering program. The purpose of the paper is to present the objectives of the Holtby endowed chair, highlight the student accomplishments during the first year the chair came into being, and articulate a vision for use of endowment funds to facilitate student learning and faculty development in a student-centered environment.

\section{Academic Endowments}

An endowment fund designated as such by the donor preserves the principal amount while using investment returns for immediate needs. A large endowment is seen as a measure of the success of a university's fiscal management policies and power of its alumni and donor base. There usually is stiff competition among universities to have the largest endowment. Unfortunately, huge endowments also tie a university's fortunes too closely to the vicissitudes of the financial markets that usually do not represent a university's true vision and mission. While top private institutions pursue fundraising with a legacy of wealth and powerful alumni on their side [2], smaller public universities, particularly those like UW-Stout that chiefly educate regional firstgeneration college students, encounter enormous challenges in building even much smaller endowments. Public universities have almost always had smaller endowments than private schools but they have experienced higher tuition increases [3]. Endowment growth is seen to protect universities from competitive forces and sustain them on fiscal rainy days. Recently, an impression has been gaining ground in public that universities are hoarding more than they are spending on educational goals. It was reported that in 2007, colleges and universities distributed 
just 3.9 percent of their endowment on activities related to their mission [4], even less than they distributed the previous year.

Academic endowments are envisioned to promote academic excellence. As such, therefore, preserving excellence of academic programs should be a higher priority than preserving capital. It is in this context that some comprehensive public universities including UW-Stout have achieved a measure of success. While striving to increase their net assets in a highly competitive economy and presiding over much smaller endowments than most private institutions, they have used their limited endowments to promote academic excellence by funding academic programs and projects and creating new opportunities for students, faculty and staff to engage in teaching, learning and professional development via scholarships, fellowships, and endowed chairs. The bottom line is: a university's mission is service, not piling up treasure [5], and some small comprehensive universities are doing an excellent job in serving this mission.

\section{Holtby Endowment - Vision and First-Year Accomplishments}

Formal coursework rigidly structured around a syllabus and focused on content delivery with strict adherence to the syllabus seldom provides the extended time and stress-free environment conducive to learning and exploration. It often takes away from the fun and excitement of learning and stifles creativity and imagination that, if properly nurtured, could lead to real learning and innovation. The Holtby funds were intended to be used to provide the students such an opportunity for exploration and growth. The funds were envisioned to provide the time needed by the participating faculty to develop project ideas and research plans for undergraduate and graduate students to engage in research and exploration on special topics not normally covered in the current program courses. The intent was to inspire the students' creativity and imagination to conduct additional research on special topics with faculty mentors, disseminate their findings to the broader public, and earn college credit for their efforts. It is envisioned that research exposure through the Holtby funds shall also increase the content knowledge, comprehension, and retention, and influence student career choices and their professional and technical accomplishments and perceptions.

Dr. Rajiv Asthana was awarded the Fulton and Edna Holtby Endowed Manufacturing Chair in 2012 for a period of three consecutive years, in part based on his vision for use of the funds. A key objective identified by Dr. Asthana was to provide the students an exposure to those disciplinary areas and special topics represented by Stout's manufacturing engineering program that were given limited coverage within formal course work but that potentially could have a transformative effect on the students' professional growth. In the first year (2012-13) the chair was established, four faculty members participated in the program. For administrative convenience, Dr. Asthana assumed the role of the endowed chair akin to a 'principal investigator' of a grant, serving as the point-of-contact responsible for involving other program faculty to develop student projects in consultation with the department chair and manufacturing engineering program director, allocate funds, maintain oversight of the progress of work, and prepare reports. A portion of the funds were also used for student, faculty and staff professional development. 
The faculty advised a number of students in their research projects focused on mechanical design, concurrent design, manufacturing systems, research and development, and materials engineering. As an example from the materials engineering area, ceramic materials are covered very briefly in a freshmen class on engineering materials and in an upper-level class on manufacturing process engineering. It was felt that student engagement with direct and purposeful lab-based research on ceramic materials would not only introduce them to how research is conducted but also provide them some additional technical background in ceramic processing and testing. The decision to focus on ceramics was inspired also by the fact that in the recent past, some of the manufacturing program students that interned at the NASA Glenn Research Center to research ceramic materials, received high accolades from their NASA mentors for their accomplishments and contribution to NASA programs, notwithstanding their rather limited prior preparation and technical background in ceramics.

The research projects that focused on ceramic materials included: a) demonstration of barium titanate ceramic capacitors and piezoelectric transducers, b) ceramic-matrix composites, c) vacuum brazed advanced ceramic and composite joints, d) air-brazing of oxide ceramics, and e) tribology of carbide-reinforced aluminum. These student projects also provided insights into how research on ceramics can be integrated in an engineering program that is not ceramic-intensive.

There were many projects completed by students who were not participating in the Holtby Endowed Chair program, but whose research may serve as a springboard for continued work by the engineering students next year and beyond. These endeavors occurred in the areas of product development, mechanical design, concurrent design, and manufacturing systems. Specific projects included: Assistive Robotic Arm and Gear, Mobile Die-cast demonstration unit, Barrel Cam Rotating Cylinder Diesel Engine Prototype, Clean Room Conveyer, Plastic Pen Design and Manufacture Tooling, Stand-Up Paddling Rowing Rig Design, Parade Float Structure, Home Bottling Machine, Conical Hopper Automated Fabrication, Independent Suspension Design, and Automated Candy Counter. Another area of intensifying applied research activity for students is strengthening additively-manufactured parts. A number of other projects were completed by the students from four other engineering programs that are offered by the Department of Engineering and Technology, some of which are mentioned in the next section.

\section{Student Research Dissemination}

Essential to the evolving expectations of the academic career and the society served is dissemination of active-learning initiatives. The audience includes colleagues and students on campus, administrators, community members, accrediting boards, leaders of other educational institutions, and government representatives. For purposes of awareness, validation, and recruitment of prospective students, various means of dissemination were employed during this academic endowment period. Crucial to the success of this endowment was providing a venue for students to train for future communication engagements. Outlined below are initial experiences of dissemination of the results from the Holtby academic endowment and related active-learning initiatives.

The engineering and technology department delivers the technical coursework for undergraduate students seeking degrees in computer engineering, engineering technology, manufacturing 
engineering, packaging, and plastics engineering. In addition, graduate courses are offered for the customized master's degree in manufacturing engineering both on-campus and on-line. The department has hosted an open house for the general public at the conclusion of each of the last three semesters that showcased senior design and development projects, underclassmen work, interdisciplinary ventures, and the research projects resulting from the academic endowment. Students prepared posters and artifacts for display, and demonstrated apparatus that they had built during the semester (Fig. 2). The event has been scheduled on the Friday prior to Saturday graduation to attract families of graduates, who expressed sincere gratitude to the faculty for organizing the event and allowing them to see the students' work. The same date was often used for advisory board meetings, which enabled members' participation. Most importantly, being scheduled late in the semester, students were afforded more time to complete development projects. Expected attendance was written into course syllabi and students have come to appreciate the opportunity to reveal their work.

Nearly ninety posters were displayed at the most recent open house celebration, which occurred on May 10, 2013 and was sustained for over four hours. The number of participating students was estimated at 250 with approximately 300 visitors.
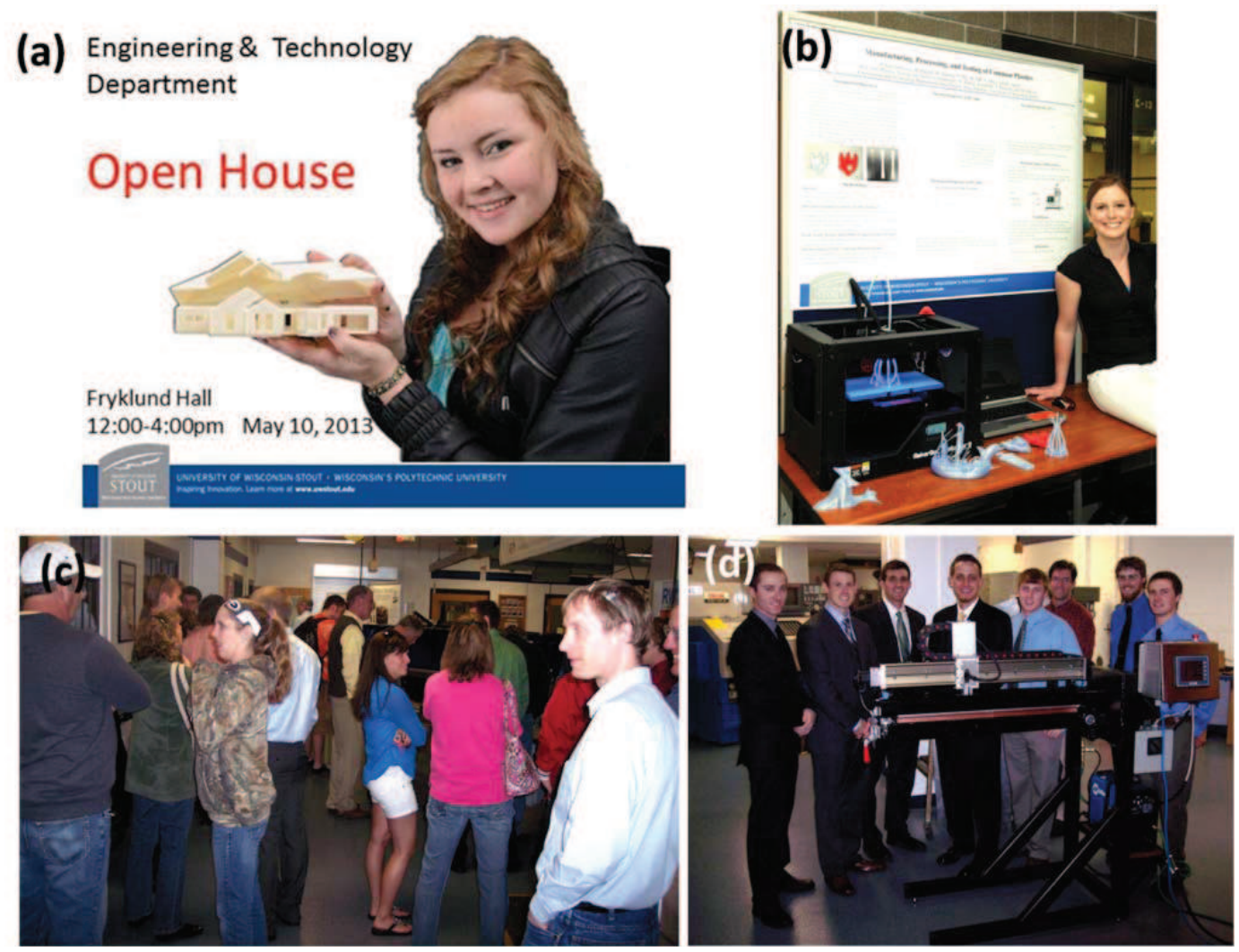

Fig. 2 (a) Postcard sent to families of graduates, regional high schools, press, administrators, retirees, advisory board members, and government officials, (b) Undergraduate Savanna Daley demonstrates her 3d printer and displays related research during Engineering and Technology Department Open House, May 2013, (c) Crowd gathers in capstone development area during Engineering and Technology Department Open House, May 2013, and (d) Manufacturing Engineering senior capstone group poses with automated welding apparatus, which was design and built by them in 2012. Engineering and Technology Department Open House, December 2012. 
Demonstrations of student-built apparatus included a photovoltaic tracker system, quality control system for a hydrogen fuel cell, advanced process control for injection molding, brain computer interface to control a radio-controlled car, sustainability education outreach: watersheds, $\mathrm{CNC}$ tube plasma cutter, food packaging for outer space, shaken baby simulator, multi-cylinder steam engine, master/slave robot, and many others. While not all of the listed projects were directly funded through the endowed chair program, a portion of the funds was used to prepare for and organize the 'E\&T Department Open House,' which exemplified the spirit and intent of the award via research and exploration. The research projects completed by students participating in the academic endowment were strategically located together for the open house. Seeing the work displayed by this group of scholars generated enthusiasm among the underclassmen and motivation to pursue similar opportunities. Documentation of the events was accomplished through compilation of U-tube videos made from a series of still photos, which were posted on the department's web site.

Dissemination of special engineering education topics under the auspices of the endowment was welcomed by government officials and university administrators, especially when students were making the presentations. While many representatives visited the open house, it was determined that an appearance at legislative offices would bring heightened awareness of the initiative of the academic endowment.

Throughout the year, professional and educational organizations sponsor and coordinate several Congressional Visit Days. Participants discuss the importance of federally funded research with their legislators and staff and inform them of related happenings in their home district. The Science, Engineering and Technology Congressional Visits Day (SET CVD) is an annual twoday event that brings scientists, engineers, researchers, educators, and technology executives to Washington, DC to raise visibility and support for science, engineering, and technology. The SET CVD is usually held in mid-March and is coordinated by a coalition of companies, educational institutions, and professional societies such as American Institute of Physics, Council for Chemical Research, and IEEE-USA. The American Geosciences Institute, in collaboration with many other geoscience societies, coordinates the annual Geosciences Congressional Visits Day (GEO-CVD) in the fall. The Material Advantage Student Program coordinates Congressional Visit Days in mid-April for members of The American Ceramic Society, Association for Iron \& Steel Technology, The Materials Information Society, and The Minerals, Metals and Materials Society.

One of the scholars that participated in the academic endowment and a member of the faculty traveled to Washington, DC during the Material Advantage Congressional Visit Days, 2013. The Material Advantage students were tasked with contacting the offices of their Representatives and Senators to arrange visits. A pre-visit meeting and dinner was held where it was stressed that students were not to lobby on behalf of a specific project (SBIR or other pending NSF grants) but instead were to advocate for long-term funding for science, engineering, and technology research. Meetings were arranged with the student's Congressman and staff of one of the Senators. A drop-in visit was made to the other Senator's staff, who was unable to be scheduled. In addition to advocating for continued funding, the student and faculty member chose to highlight the research emanating from the academic endowment through discussion and by giving a postcard "leave behind" describing the research. They also invited the individuals to the 
upcoming open house, and provided a gift of thanks from the home district to the Congressman (Fig. 3). All seemed genuinely interested in the research ongoing in their State and did send staff members to the open house. The two also met with students and faculty from other universities to discuss materials-related research, and recruit for UW-Stout's M.S. in manufacturing engineering program.

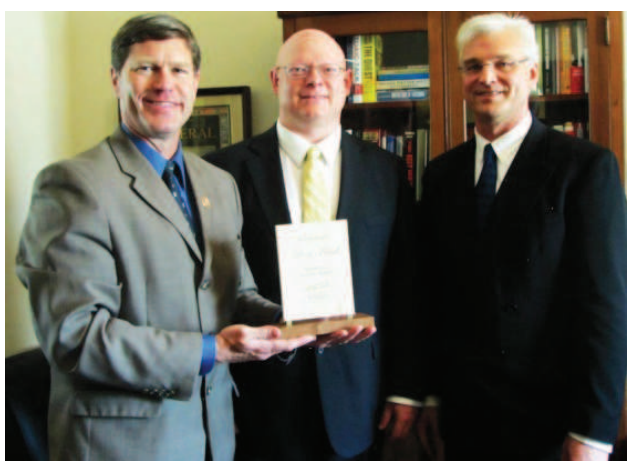

Fig. 3 Congressman Ron Kind (left) meets with research assistant Timothiax

Shoushounova and faculty member Jerry Johnson during Congressional Visit Days.

A number of manufacturing engineering students also presented posters on their research at the University-wide Research Day in April (Fig. 4) and at STEM Student Project Expo in May. Five students who had completed their research projects are currently preparing research manuscripts for review and possible publication in the university's Journal of Student Research.
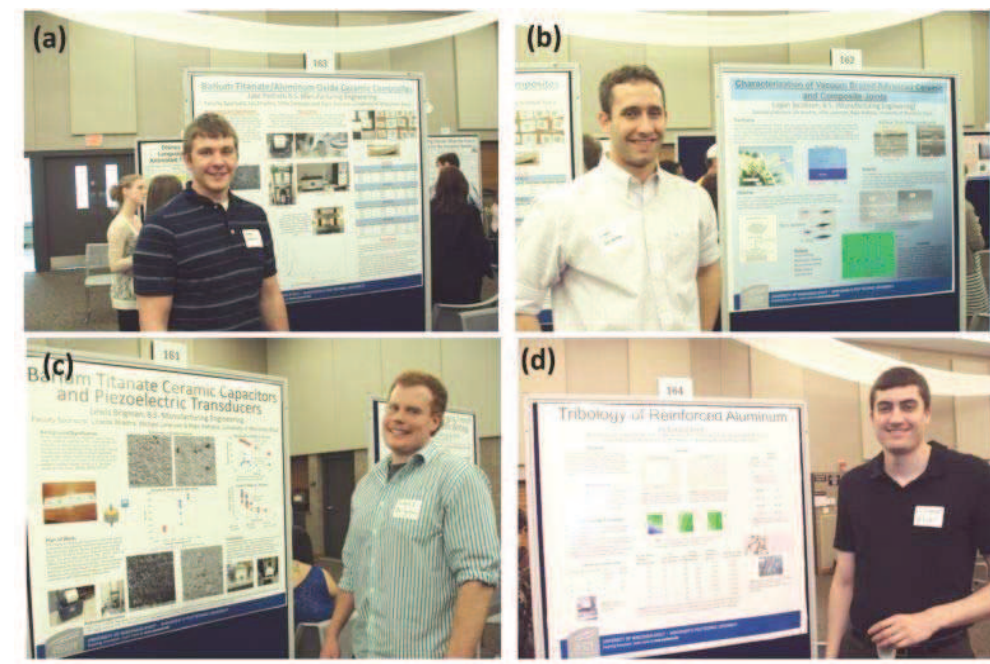

(d)
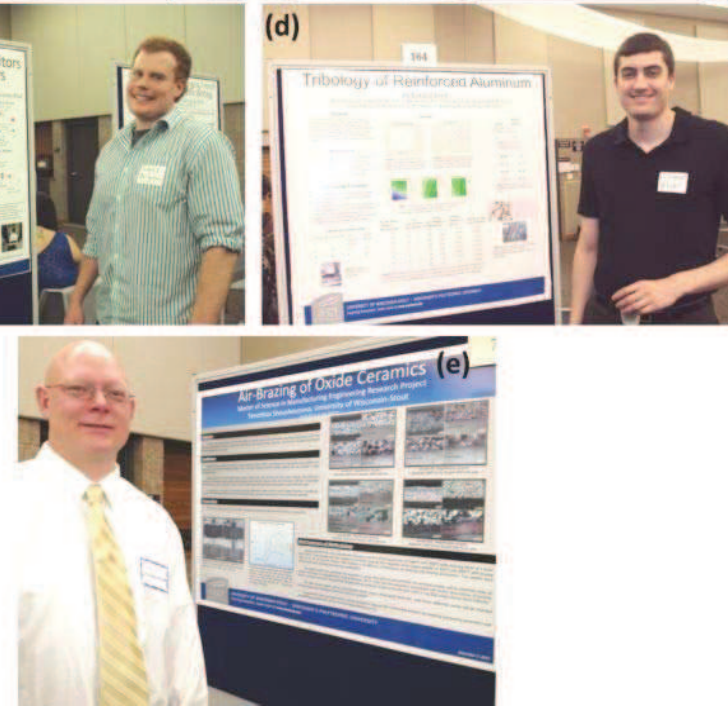

Fig. 4 Students that participated in the Fulton and Edna Holtby Endowed Chair program and their research posters at UW-Stout Research Day. 


\section{Summary and Prospects}

The academic year 2012-13 was the first time the Fulton and Edna Holtby Manufacturing Endowed Chair program was run. Four faculty members participated in the program and advised student research and dissemination activities. Through the endowment, students were given the opportunity to explore topics that inspired their creativity and imagination. The expectation that the results of their work would be disseminated at various venues was met with grateful anticipation. Very few problems arose in running the program except for an untimely oven thermocouple malfunction. There is continuing work by the faculty involved in the program to develop additional projects and help students with the dissemination activities to provide greater visibility to the students' technical achievements. Success in securing future endowments will certainly be enhanced through dissemination of the results from current endowments, which appears best accomplished by the student ambassadors.

A key measure of success in using the funds was dissemination of student and faculty research. To that end, a number of students presented their projects at one or more of the following events: STEM Expo, E\&T Open House, Stout Research Day, capstone presentation, presentation at national meetings, and publications in J. Student Research (to be submitted by Oct 01, 2013).

This first year was an attempt to establish baseline information and institute metrics such that future activities might be measured against these initial happenings. It is proposed to subsequently employ a revised Developing a Curriculum (DACUM) method upon reflections from first-year activities. While The DACUM process is often used for occupational analysis, it can also be a strategy for developing curriculum and assessment methods related to open-ended research [6].

DACUM uses a facilitator to direct panel members in analyzing their job-related tasks through a brainstorming process. The result is a list of competencies that describes the specific duties and tasks of competent workers in a specific job classification. Following the first year activities of the Holtby Endowed Chair, participants (students and faculty) will prepare the first draft of the list of core competencies and subsequently have paraprofessionals (people working in the field, researchers, and practitioners or members of the selection committee) validate the list. The students in subsequent years then shall have a list of things in which they will strive to become competent and accurate metrics can be employed.

The vision for the Fulton and Edna Holtby endowed funds to bring research experiences to the student shall contribute to the university's goal to facilitate research and enquiry, and create a more scholarly atmosphere on campus. It is hoped that focused learning via Holtby funds shall inculcate the spirit of inquiry and a sustainable approach to learning that would last a lifetime. 


\section{References}

[1] Linards Stradins, Program Review Report, Bachelor of Science in Manufacturing Engineering, Dec 2012

[2] Reginald Stuart, Colleges and Universities Work to Build Endowments After Recession, May 06, 2013, Diverse (issues in higher education), http://diverseeducation.com/article/53126/

[3] Josh Lerner, Antoinette Schoar, and Jialan Wang, Secrets of the Academy: The Drivers of University Endowment Success, 09-024, working paper, 2008, Harvard Business School, http://www.hbs.edu/faculty/ Publication\%20Files/09-024.pdf

[4] Charles Miller and Lynne Munson, University Endowment Reform - A Dialogue, Remarks from the American Enterprise Institute conference 'University Endowments: Their Role in Higher Education and Possibilities for Reform,' Center for College Affordability and Productivity, April 2008

[5] Peter Coy, Academic Endowments: The Curse of Hoarded Treasure, Bloomberg Business week, on March 01, 2009 http://www.businessweek.com/stories/2009-03-01/academic-endowments-the-curse-of-hoardedtreasurebusinessweek-business-news-stock-market-and-financial-advice

[6] The Ohio State University, College of Education and Human Ecology, The DACUM Process, retrieved September 2013. (http://www.dacumohiostate.com/process.htm). 